\title{
Impacts of greenhouse gases and aerosol direct and indirect effects on clouds and radiation in atmospheric GCM simulations of the 1930-1989 period.
}

\author{
JoHANNES QuAas \\ OLIVIER BOUCHER \\ JeAn-Louis Dufresne \\ Hervé Le Treut \\ johannes.quaas@1md.polytechnique.fr \\ +33(0)169333199 \\ $+33(0) 169333005$ \\ Laboratoire de Météorologie Dynamique, IPSL/C.N.R.S., Paris, France \\ Laboratoire d'Optique Atmosphérique, Unversité de Lille/C.N.R.S., Villeneuve \\ d'Ascq, France
}

\begin{abstract}
Among anthropogenic perturbations of the Earth's atmosphere, greenhouse gases and aerosols are considered to have a major impact on the energy budget through their impact on radiative fluxes. We use three ensembles of simulations with the LMDZ general circulation model to investigate the radiative impacts of five species of greenhouse gases $\left(\mathrm{CO}_{2}, \mathrm{CH}_{4}, \mathrm{~N}_{2} \mathrm{O}, \mathrm{CFC}-11\right.$ and $\left.\mathrm{CFC}-12\right)$ and sulfate aerosols for the period 1930-1989. Since our focus is on the atmospheric changes in clouds and radiation from greenhouse gases and aerosols, we prescribed sea surface temperatures in these simulations. Besides the direct impact on radiation through the greenhouse effect and scattering of sunlight by aerosols, strong radiative impacts of both perturbations through changes in cloudiness are analysed. The increase in greenhouse gas concentration leads to a reduction of clouds at all atmospheric levels, thus decreasing the total greenhouse effect in the longwave spectrum and increasing absorption of solar radiation by reduction of cloud albedo. Increasing anthropogenic aerosol burden results in a decrease in high-level cloud cover through a cooling of the atmosphere, and an increase in the low-level cloud cover through the second aerosol indirect effect. The trend in low-level cloud lifetime due to aerosols is quantified to 0.5 min day ${ }^{-1}$ decade $^{-1}$ for the simulation period. The different changes in high (decrease) and low-level (increase) cloudiness due to the response of cloud processes to aerosols impact shortwave radiation in a contrariwise manner, and the net effect is slightly positive. The total aerosol effect including also the aerosol direct and first indirect effects remains strongly negative.
\end{abstract}




\section{Introduction}

Looking back at the twentieth century, and more precisely, at the 1930 to 1989 period, the observed warming on the global scale has been less than expected due to the anthropogenic greenhouse effect. Additional anthropogenic forcing by sulfate aerosols has been proposed as a negative forcing which partially counterbalanced the warming effect of greenhouse gases (Wigley, 1989; Charlson et al., 1989). In this study, we analyse the impact of greenhouse gases and aerosols on the Earth's radiation budget, with a focus on indirect or feedback effects by modification of cloud properties.

Anthropogenic greenhouse gases consist of carbon dioxide from fossil fuel combustion and biomass burning, and other gases like methane, nitrous dioxide, chlorofluorocarbons, and tropospheric ozone. These gases are responsible for a warming of the Earth's surface because of enhanced atmospheric absorption and re-emission at lower temperatures of longwave (LW) radiation in the troposphere. The combustion of (sulfur-containing) fossil fuel is also a major source for sulfate aerosols. Aerosols scatter sunlight and enhance the planetary shortwave (SW) albedo, an effect known as the "aerosol direct effect" (ADE). In addition, by their ability to act as cloud condensation nuclei, (hygroscopic) aerosols change cloud properties, producing essentially an increase in cloud albedo. These processes are called "aerosol indirect effects" (AIE). As it has been shown by field studies (e.g., Brenguier et al., 2000; Ramanathan et al., 2001) and satellite observations (e.g., Coakley et al, 1987; Kaufman and Nakajima, 1993; Bréon el al., 2002), the cloud droplet effective radius, $r_{e}$, decreases with increasing aerosol concentration. For constant liquid water content, this results in a larger cloud albedo (this effect is called the first AIE; Twomey, 1974). Smaller droplets are less likely to collide, therefore delaying or suppressing rainforming microphysical processes. This results in a longer cloud lifetime and thus larger cloud liquid water content, which again results in a larger cloud albedo (called the second AIE; Albrecht 1989). Such an effect has been put into evidence by Rosenfeld (2000) using satellite observations of clouds in various polluted and unpolluted conditions. 
It is useful at least in the framework of the modelling of external influences on the climate to introduce the concept of radiative forcing provoked by an external perturbation. The radiative forcing, $F$, is defined as the difference in radiative flux at the tropopause in perturbed and unperturbed conditions, while the temperature and humidity profiles in the troposphere are fixed. In this definition, e.g. used by the Intergovernmental Panel on Climate Change (Ramaswamy et al., 2001), any „small“ global mean radiative forcing in a GCM is directly related to a change in global mean surface temperature at equilibrium through a modeldependent parameter $\lambda$ :

$$
T_{s}=F
$$

\section{Equation 1}

The largest radiative forcing is due to the anthropogenic greenhouse effect, with a positive annual global mean of the order of $2.4 \mathrm{Wm}^{-2}$ for greenhouse gas concentrations of the end of the $20^{\text {th }}$ century compared to pre-industrial conditions (e.g., Ramaswamy et al., 2001). The annual global mean radiative forcing by the sulfate aerosol direct effect is estimated to be about of $-0.5 \mathrm{Wm}^{-2}$, the forcing by the first AIE to be of the order $-1.0 \mathrm{Wm}^{-2}$, although both are very uncertain (Boucher and Haywood, 2001).

General circulation models (GCMs) that simulate the dynamical and physical processes on a global scale are suitable tools to understand and possibly predict the impact of anthropogenic climate perturbations. Using an atmospheric GCM, we try to understand the role greenhouse gases and aerosol effects have played in the evolution of the climate of the last century. We focus on changes in radiative fluxes throughout the simulation period of 1930-1989.

The radiative forcings due to greenhouse gases and the aerosol direct and first indirect effects are computed. The second indirect effect, however, cannot be diagnosed instantaneously as it is related to a time-evolving process. There has been some controversy whether it should be considered as a forcing or a feedback mechanism. Rotstayn and Penner (2001) define a quasi-forcing for the second AIE as the 
difference in radiative flux between two model integrations with fixed SST, which are identical except of a change in the aerosol concentration in the precipitation parameterisation. They showed that, at least for the first AIE, the quasi-forcing was a good estimate of the actual radiative forcing compiled for fixed profiles of temperature and humidity.

In analogy to this, we introduce the „radiative impact" of an anthropogenic perturbation. This is defined as the difference in the radiative flux between two simulations with transient SSTs, with and without the perturbation, but otherwise identical. We compute the radiative impact due to greenhouse gases, and the total aerosol radiative impact, including the aerosol direct and both indirect effects. This enables us to compare the radiative forcing due to greenhouse gases and aerosol direct and first indirect effects to the radiative impact of greenhouse gases and aerosols, which includes feedback processes.

In this paper we have chosen to analyse an ensemble of GCM simulations using the LMDZ GCM in response to imposed SSTs. We have used prescribed SSTs as a manner to constrain the model and diagnose the forcings and feedbacks in conditions as close as possible to the actual conditions throughout the 20th century. For the same reason, our reference simulation is a simulation where observed or analysed greenhouse gases and aerosols are being used. In order to isolate the impacts of aerosols and greenhouse gases, we have also added two more sets of simulations where we fix first the aerosol distributions and then the greenhouse gas concentrations to pre-industrial values.

The response of the temperature over the continents, the cloud feedbacks, and the aerosol indirect effects to some degree might be different for other models. However, the design of the experiments allows us to diagnose them in climate conditions as close as possible from the real ones.

In Section 2, we describe the general circulation model LMDZ and the set-up of the simulations in detail as well as our methods to analyse the radiative impacts of 
the imposed anthropogenic forcings. In Section 3, the results for these radiative impacts are presented and analysed for the solar and terrestrial spectra. We discuss these findings in Section 4, showing the impact of cloud cover changes and particularly the second aerosol indirect effect.

\section{Model description}

\section{The atmospheric model}

The model used is the atmospheric general circulation model (GCM) of the Laboratoire de Météorologie Dynamique (LMD). It is a grid-point model, which we ran in a resolution of $96 \times 73$ points on a regular longitude-latitude horizontal grid with 19 hybrid sigma-pressure coordinate levels. The time-step is $6 \mathrm{~min}$ for the dynamical part of the model and $30 \mathrm{~min}$ for the physics. Prognostic variables are temperature, horizontal winds, surface pressure, and total water content.

The physics of the model has formerly been described e.g. in Li (1999) and is reported briefly. Radiative transfer is calculated in the model using an advanced version of the scheme of Fouquart and Bonnel (1980) for the solar spectrum and an updated version of the code of Morcrette (1991) for the terrestrial part. In contrast to former studies (e.g., Le Treut et al., 1998), the diurnal cycle is included. Convection is parameterised in the model using the mass-flux scheme of Tiedtke (1989). The land surface processes are parameterised through a bucket model, and the surface temperature is evaluated in the boundary layer scheme using the surface energy balance equation.

Condensation of water vapour is calculated using a ,top-hat“ probability density function for total water content to allow for fractional cloudiness (Le Treut and $\mathrm{Li}$, 1991). We apply the cloud microphysical scheme of Boucher et al. (1995), which includes autoconversion and accretion for liquid water clouds and a simple snowformation equation for ice clouds. 


\section{Parameterisation of the aerosol indirect effects}

The cloud droplet number concentration $\left(N_{d}\right.$, in $\left.\mathrm{cm}^{-3}\right)$ is diagnosed from the sulfate aerosol mass concentration, $m_{\mathrm{SO}_{4}}\left(\mu \mathrm{g} \mathrm{m} \mathrm{m}^{-3}\right)$ using an empirical formula (Boucher and Lohmann, 1995; formula „D“):

$$
N_{d}=10^{2.21+0.41 \log \left(m_{a}\right)}
$$

\section{Equation 2}

A minimum (background) cloud droplet number concentration of 20 particles $\mathrm{cm}^{-3}$ is applied to avoid unrealistically small droplet number concentrations in regions where very few sulfate aerosols are present.

The volume-mean cloud droplet radius for liquid water clouds assuming spherical particles is

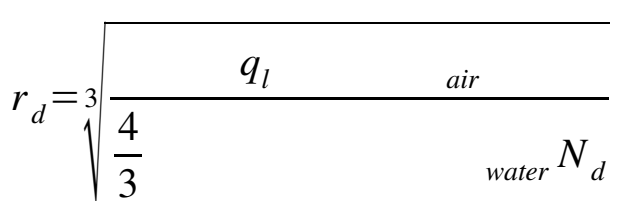

Equation 3

where $q_{l}$ is the liquid water mixing ratio, and

air and

water the densities of air and water, respectively. From the combination of Eqs. 2 and 3 it can be deduced that an increase in sulfate aerosol mass concentration directly results in a decrease in the cloud droplet radius for constant liquid water content. The "effective" cloud droplet radius, $r_{e}$, defined as the ratio of the third to the second moment of the droplet size distribution, is parameterised as $r_{e}=1.1 r_{d}$ (Pontikis and Hicks, 1993).

The cloud property relevant to the radiation transfer in the solar spectrum is the cloud optical thickness, $\tau$. This quantity relates aerosols, clouds, and radiation in our model. Cloud optical thickness is parameterised in terms of $r_{e}$ and the cloud liquid water path, $W$, in each layer (Stephens, 1978):

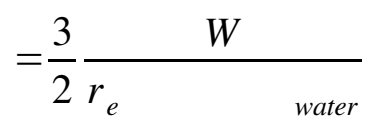

Equation 4 
The autoconversion, $R_{l l}$, of liquid water droplets to raindrops in the Boucher scheme depends on the cloud droplet radius

$$
R_{l l} \propto E_{l l} q_{l} r_{d}^{4} N_{d}
$$

Equation 5

where $E_{l l}$ is the collision efficiency, which is considered to be 0 for droplet radii less than a "critical radius", $r_{\text {crit }}$, and 1 for larger droplets. For constant $q_{l}$, $r_{d} \propto N_{d}^{-1 / 3}$ and thus $R_{l l} \propto r_{d}$ for $r_{d}>r_{c r i t}$. The conversion of cloud to rain water is thus less efficient for smaller droplets. The optical thickness and thus the cloud albedo is increased by the first AIE by decreasing $r_{e}$ and by the second AIE by increasing $W$.

\section{Figure 1 so4ghg.eps}

\section{Experiment set-up}

The simulations were done using time-varying observed sea surface temperature (SST) and sea-ice extent distributions from Hadley-Centre analyses

(HADISST1.1; Rayner et al., 2003) for the period 1930-1989. The monthly mean distributions are smoothed out in time. Using observed SST distributions rather than an interactive ocean model has some advantages. Firstly, we reduce the degree of freedom of the model considerably, enabling more unambiguous analyses. Secondly, the real climate evolution is already imposed to a certain degree, so some feedback processes due to radiative impacts can be analysed under more realistic conditions. Finally, this model configuration is computationally relatively inexpensive and a larger number of simulations can be performed.

Monthly mean sulfate aerosol distributions are imposed, which have been precomputed every 10 -years of the simulation using historical emission data and applying a sulfur cycle model (Boucher et al., 2002; Boucher and Pham, 2001). Natural and anthropogenic sources for sulfate aerosols are considered. The monthly distributions are linearly interpolated in between each decade. As far as the direct effect is concerned, there is an assumption on the sulfate size distribution in order 
to convert sulfate aerosol mass to sulfate aerosol optical depth. We use a lognormal size distribution with geometric volume diameter of $0.3 \mu \mathrm{m}$ and geometric standard deviation of 2.0 for dry sulfate. Growth with relative humidity is allowed (see Boucher and Anderson, 1995, for details). As far as the indirect effect is concerned, there is no implicit assumption on size distribution as we use an empirical relationship between sulfate mass and cloud droplet number concentration (Boucher and Lohmann, 1995). Here, we use sulfate aerosols only, as variations of other aerosol species during the $20^{\text {th }}$ century are not well known. Il will be however very valuable to include carbonaceous aerosols from fossil fuel and biomass burning when historical emissions become available for the $20^{\text {th }}$ century.

Figure 1 shows the global and annual mean sulfate aerosol mixing ratio at 850 $\mathrm{hPa}$. Greenhouse gases are considered well mixed throughout the troposphere in our model. We use yearly mean averages of $\mathrm{CO}_{2}, \mathrm{CH}_{4}, \mathrm{~N}_{2} \mathrm{O}, \mathrm{CFC}-11$ and CFC-12 from Myhre et al. (2001) (Fig. 1). A similar model set-up has been used recently by Sexton et al. (2003) for the purpose of diagnostics of different anthropogenic radiative forcings.

\section{Table 1}

We carried out three ensembles of simulations, each consisting of three members with slightly different initial conditions for $1^{\text {st }}$ January 1930 . In the first, named GHG+AER, greenhouse gases as well as sulfate aerosol concentrations were varying as described above. In the second, named GHG, sulfate aerosols were fixed to the calculated pre-industrial distribution (i.e., using natural aerosol sources only), while greenhouse gas concentrations increased during the simulation. Finally, we did a control simulation, CTL, in which both sulfate aerosols and greenhouse gas concentrations were fixed to their pre-industrial concentrations. A summary of the ensembles is given in Table 1 .

\section{Table 2}


Throughout this paper, the abbreviations GHG and AER in capitals will refer to the scenarios, whereas ghg (,greenhouse gases“) and aer (,,aerosols“) in lower case refer to the perturbations of the atmospheric concentrations themselves.

\section{Radiation diagnostics}

The influence of greenhouse gases and aerosols on the radiative fluxes in our model is examined using two different approaches. Firstly, we calculate the radiative forcings, as defined in the introduction. Secondly, we define a radiative impact, a new quantity which includes some feedback processes of the climate system. The shortwave and longwave spectra are treated separately, as are the perturbations by greenhouse effect and different aerosol effects.

\section{Radiative forcings}

For the greenhouse effect, the radiative forcing is calculated off-line using the temperature and humidity profiles and the cloud and surface properties for each month of the simulations. The difference in longwave radiative flux at the tropopause between current and pre-industrial ghg concentrations is computed after adjustment of the stratosphere profiles (Cess et al., 1993, Hansen et al., 1997).

Concerning the aerosol effects, the shortwave radiative forcings due to the aerosol direct and first indirect effects are calculated on-line in the simulation. The radiation scheme is applied twice, with the aerosol and cloud optical properties for current and pre-industrial aerosol distributions, and the difference in SW radiative fluxes at the top of the atmosphere (TOA) is taken as the radiative forcing. This implicitly neglects the adjustment of the stratosphere temperature and humidity profiles, which is a valid assumption for the SW spectrum (Hansen et al., 1997). The radiative fluxes computed with the current aerosol concentrations are used in the integration, while the fluxes calculated with pre-industrial values are just stored for the analysis. 


\section{Radiative impacts}

In order to include the impact of changing cloud properties and (other) feedback processes in our analysis, we define a new quantity, the „radiative impact“ of a given perturbation $\left(I_{\text {perturbation }}\right)$. We define this radiative impact as the difference in radiative fluxes, $F$, between two scenarios, in which all but one parameter of the simulation are fixed and the internal variability of the model is removed by averaging over an ensemble of simulations.

According to this definition, the total sulfate aerosol radiative impact, $I_{a e r}$, is the difference in radiative fluxes between the GHG+AER and GHG simulations. Please note that the radiative impact of aerosols might be calculated differently by carrying out another set of simulations with anthropogenic aerosols and with preindustrial greenhouse gases, potentially yielding results slightly different from those by our analysis. However, here, we are rather interested in the impacts of aerosols on radiation and clouds in the framework of increasing greenhouse gas concentrations to analyse their effects on anthropogenic climate change. The radiative impact of aerosols is composed of the aerosol direct effect as well as the first and second aerosol indirect effects, and it possibly includes further feedback processes due to aerosols. Similarly, we define the radiative impact of greenhouse gases, $I_{g h g}$ (see Table 2 for a summary).

In the shortwave spectrum, we compare the net radiative fluxes at the top of the atmosphere in two ensembles. In the longwave spectrum, however, we have to deal with the fact that over the oceans, the surface temperature is imposed on the model and may thus not adjust to get the radiative budget at the top of the atmosphere to equilibrium. We therefore use in the terrestrial spectrum the difference between the upward radiative flux at the surface and the outgoing longwave radiation (OLR) as the radiative flux in the definition of the LW radiative impact. This difference may be interpreted as the total atmospheric greenhouse effect (GHE). The upward LW flux at the surface is the sum of the thermal emission of the surface and the reflected fraction of the atmospheric thermal emission reaching the surface. The GHE can therefore be written as 


$$
G H E=\left(T^{4}+(1-\quad) F_{s f C} \downarrow\right)-F_{T O A} \uparrow
$$

Equation 6

where $\varepsilon$ is the surface emissivity, $\sigma$ the Stefan-Boltzmann constant, $T_{s f c}$ the surface temperature, and $F_{s f c} \downarrow$ and $F_{T O A} \uparrow$ the radiative fluxes at the surface (downwelling) and the top of the atmosphere (upwelling), respectively.

We use the subscripts ,aer“ and ,ghg“ to denote the radiative impacts of aerosols ( $\left.I_{\text {aer }}\right)$ and greenhouse gases $\left(I_{\mathrm{ghg}}\right)$, respectively, and superscripts to refer to all-sky $\left(I^{\mathrm{a}}\right)$, cloud-covered $\left(I^{\mathrm{cc}}\right)$, and cloud-free $\left(I^{\mathrm{cf}}\right)$ conditions.

\section{Results}

\section{Figure 2}

In Fig. 2, the temporal evolution of the global annual mean radiation fluxes at TOA is shown. The shaded areas depict the envelopes of the ensemble members of each of the scenarios. As the three scenarios are clearly distinguished, we conclude that the number of three ensemble members is sufficient to distinguish differences in radiative quantities between the three scenarios. Note that the fluxes at TOA are not necessarily in equilibrium because the surface temperature over oceans is fixed.

\section{Figure 3}

\section{Radiative forcings}

Figure 3 shows the radiative forcings in the scenario simulation GHG+AER. The greenhouse gas forcing in the model is positive and ranges from $0.74 \mathrm{Wm}^{-2}$ in 1930 to $2.07 \mathrm{Wm}^{-2}$ in 1989 , which is in good agreement to the value of $2.43 \mathrm{Wm}^{-2}$ given by the IPCC for the anthropogenic greenhouse gas forcing at the end of the $20^{\text {th }}$ century (Ramaswamy et al., 2001). The direct forcing by sulfate aerosols decreases from -0.2 to $-0.5 \mathrm{Wm}^{-2}$ and the first aerosol indirect forcing from -0.6 to $-1.3 \mathrm{Wm}$

2. This is also in the range of results compiled by Ramaswamy et al. (2001) (-0.2 to $-0.8 \mathrm{Wm}^{-2}$ for the $\mathrm{ADE}$ and -0.3 to $-1.8 \mathrm{Wm}^{-2}$ for the first AIE). 
If the three forcings add up linearly, the total forcing would be slightly negative for the period 1930-1980 (with a minimum of $-0.25 \mathrm{Wm}^{-2}$ in 1956), and positive afterwards (up to $0.27 \mathrm{Wm}^{-2}$ in 1989). The derived net forcing seems to be in remarkable agreement with the observed global mean temperature evolution (Folland et al., 2001), even though some natural forcings are not considered here. However, natural forcings (variations in solar irradiance and volcanic eruptions) did not play an important role in the period of interest, except for a negative forcing due to the Agung (Indonesia) eruption in 1963, which caused a negative radiative forcing for about 5 years (Myhre et al., 2001).

Figure 3 also shows the greenhouse gas LW radiative forcing restricted to cloud free conditions. This quantity is about 0.1 to $0.2 \mathrm{Wm}^{-2}$ larger than its all-sky counterpart. The explanation is that (high level) clouds themselves cause a greenhouse effect and thus mask part of the greenhouse effect due to anthropogenic greenhouse gases.

\section{Radiative impacts}

\section{Figure 4}

\section{The longwave spectrum}

In Fig. 4, the LW radiative impacts of greenhouse gases and aerosols are shown. The LW radiative impact of the aerosols is negligible. A trend of about $0.2 \mathrm{Wm}^{-2}$ decade $^{-1}$ is simulated for the radiative impact of greenhouse gases with very similar values for all-sky and cloudy-sky conditions. The radiative impact in cloud-free conditions, $I_{g h g}^{c f}$, is about 0.2 to $0.5 \mathrm{Wm}^{-2}$ larger.

The analysis of the greenhouse gas radiative impacts in all-sky, cloud-covered, and cloud-free conditions enables us to investigate cloud feedback processes, which will be analysed in further detail in the following section. 
Note first that (high-level) clouds exert themselves a greenhouse effect. Thus, generally, the total atmospheric greenhouse effect is larger in cloud-covered compared to cloud-free conditions $\left(G H E^{\mathrm{cc}}>G H E^{\mathrm{cf}}\right)$. As noted in the previous section in the description of the radiative forcing of the anthropogenic greenhouse gases, the radiative effect of greenhouse gases is larger in cloud-free compared to cloud-covered conditions as clouds mask part of the greenhouse effect by the anthropogenic greenhouse gases. However, the difference between cloud-free and cloud-covered conditions is somewhat larger for the radiative impact ( 0.23 to 0.49 $\mathrm{Wm}^{-2}$, Fig. 3) than for the radiative forcing (0.13 to $0.37 \mathrm{Wm}^{-2}$, Fig. 2), and the trend in this difference is slightly larger for the radiative impact than for the radiative forcing. This is due to a slight cloud feedback, which is included in the radiative impact, but not in the radiative forcing. It implies that the anthropogenic increase in greenhouse gas concentrations in our model results in a slight decrease in the greenhouse effect of clouds due to a decrease in their water content.

Given that the greenhouse gas radiative impact is equal in all-sky and cloudcovered conditions, that it is larger in cloud-free than in cloud-covered conditions, and that the greenhouse effect in cloud-covered conditions is generally larger than in cloud-free conditions, we find that in addition to the reduction in the greenhouse effect of the clouds when they are present, the cloud fraction is reduced in our model due to the anthropogenic greenhouse gases (for more details, see the following section).

Formally we can write the all-sky GHE as the sum of the GHE in the cloudcovered, GHE ${ }^{\mathrm{cc}}$, and in the cloud-free part of a grid cell, GHG ${ }^{\text {cf }}$, where each of the contributions is weighted by the respective fraction of the grid-cell, cloudy and clear, $f$ and $(1-f)$, respectively:

$$
G H E^{a}=f G H E^{c c}+(1-f) G H E^{c f}
$$

Equation 7

The all-sky radiative impact of greenhouse gases ( $I_{\text {ghg }}^{a}=G H E_{G H G}^{a}-G H E_{C T L}^{a}$; see section 2.4.2), is thus influenced by the difference in GHE in cloudy and cloud free conditions, and by the change in cloud cover, $f_{g h g}=f_{G H G}-f_{C T L}$ : 


$$
\begin{aligned}
& I_{g h g}^{a}=f_{G H G} G H E_{G H G}^{c c}+\left(1-f_{G H G}\right) G H E_{G H G}^{c f}-f_{C T L} G H E_{C T L}^{c c}-\left(1-f_{C T L}\right) G H E_{C T L}^{c f} \\
& \dot{i} I_{g h g}^{c f}\left(1-f_{G H G}\right)+I_{g h g}^{c c} f_{G H G}+f_{g h g}\left(G H E_{C T L}^{c c}-G H E_{C T L}^{c f}\right)
\end{aligned}
$$

Equation 8

We noted that $I_{\text {ghg }}^{a} \simeq I_{\text {ghg }}^{c c}$ and $I_{\text {ghg }}^{c f}>I_{\text {ghg }}^{a}$, and that generally $G H E^{c c}>G H E^{c f}$.

Thus, $f_{g h g}$ must be negative.

We may summarize the two results that anthropogenic greenhouse gases cause the clouds to have a smaller greenhouse effect in our model (due to a decrease in cloud water content), and that they result in addition in a decrease in cloud cover.

Comparing the radiative forcing and the radiative impact (where the latter quantity includes the impact of feedback processes while the former one does not) gives an insight in the actual perturbation of the radiation due to the feedback processes.

The radiative impact of the greenhouse gases varies from $0.81 \mathrm{Wm}^{-2}$ in 1930 to $2.09 \mathrm{Wm}^{-2}$ in 1989, which is close to the corresponding diagnosed radiative forcing. Thus, the net radiative impact of these feedback processes is small in the context of fixed SST.

Looking at cloud free conditions, however, the radiative impact of greenhouse gases is larger than the corresponding radiative forcing. This small difference can be explained by the existence of a positive feedback related to an increase in water vapour concentration in a warmer atmosphere. This feedback process, however, acts over continents only, as the sea surface temperatures were the same in both scenarios.

\section{Figure 5}

\section{The shortwave spectrum}

Figure 5 shows the radiative impact in the SW spectrum. Concerning greenhouse gases, a small radiative impact is simulated for cloud-free conditions. We attribute this to a snow cover feedback (melting of snow due to the warmer surface 
temperature in the simulation including anthropogenic greenhouse gases), which is of the order of $0.1 \mathrm{Wm}^{-2}$ and exhibits a very slight trend of $0.002 \mathrm{Wm}^{-2} \mathrm{decade}^{-1}$. In cloud-covered conditions, greenhouse gases cause an increase in radiative impact, which is somewhat smaller than the increase in all-sky conditions. These two findings correspond well to what we found for the longwave radiative impacts of the anthropogenic greenhouse gases, and we thus again conclude that the increase in SW flux in cloud covered conditions corresponds to less reflecting clouds, and, as the all-sky radiative impact is larger than for both the clear and cloudy-sky radiative impact, the cloud cover must be reduced by greenhouse gases. These findings will be discussed in further detail in the following section.

Concerning aerosols, a clear-sky radiative impact is simulated, which decreases from -0.2 to $-0.5 \mathrm{Wm}^{-2}$. This is almost exactly the evolution diagnosed as the radiative forcing of the aerosol direct effect. For cloud-free conditions, it can be concluded that there is almost no net radiative impact due to feedback processes in the context of fixed SST. In cloudy conditions, the radiative impact is strongly negative and decreases from -0.8 to $-1.6 \mathrm{Wm}^{-2}$. The all-sky radiative impact lies in between the two, ranging from -0.7 to $-1.4 \mathrm{Wm}^{-2}$. This is only a little bit more than the radiative forcing diagnosed for the first AIE alone and thus much smaller than the sum of first AIE and ADE forcings. The open question is how the second aerosol indirect effect acts in our model. We investigate in Section 4.2 the feedback processes that introduce some positive radiative impact due to aerosols, and show that they counterbalance the second aerosol indirect effect over large parts of the globe in our model.

\section{Discussion}

\section{Figure 6}

\section{Table 3}




\section{Trends in cloudiness}

Figure 6 shows the evolution of the change in global annual mean cloud cover. The changes in total, low level (below $800 \mathrm{hPa}$ ), mid-level (between 800 and 450 $\mathrm{hPa}$ ) and high level (above $450 \mathrm{hPa}$ ) cloud cover are shown. The global mean values for cloud cover vary only slightly among the scenarios. These values are listed in Table 3. As already noted in the analysis of the radiative impacts in the previous section, radiative effects of anthopogenic greenhouse gases result in a decrease in cloud cover. This reduction is found for clouds at all three levels, and it is strongest for high-level clouds. While we observe an increase in water vapour content in the atmosphere, $q_{v}$, due to the increased temperature in the scenario including anthropogenic greenhouse gases compared to the control ensemble, the saturation water vapour mixing ratio, $q_{\text {sat }}$, rises as well. $q_{\text {sat }}$ depends only on temperature and in our model the cloud fraction is derived as the part of a constant probability density distribution of the total water mixing ratio, which overpasses the saturation water vapour mixing ratio. In the simulation, the effect of the $q_{\text {sat }}$ increase due to the anthropogenic greenhouse gases is larger, so that the net effect is a decrease in cloudiness. As already shown, in addition, the clouds have a smaller greenhouse effect and a smaller albedo, which can both be attributed to a smaller water content of the clouds (not shown).

\section{Figure 7}

Figure 7 shows the zonal average of the linear trends in the high, middle, and low level, and total cloudiness, computed as the slope of the linear regression of the time series at each grid point. Note that in the global mean, these trends would be the slope of the curves in Fig. 6. For the aerosol impact on cloudiness, different behaviours can be observed for clouds at different levels. High-level cloudiness decreases, whereas low and mid level cloudiness increase. For high-level clouds, the saturation water vapour mixing ratio decreases less rapidly than the total water vapour mixing ratio due to the reduction of the temperature. The result is a reduction in high-level cloudiness. The result of the competition of changes in 
water vapour concentration and saturation water vapour mixing ratio due to changes in the temperature are certainly strongly dependent on the model formulation and need to be examined further. The increase in mid- and low-level cloudiness seems to be rather due to other processes than just a feedback to the temperature decrease.

The reduction in high-level cloudiness due to aerosols does not show a uniform distribution over the globe. While sometimes even an increase can be observed (e.g., around $20^{\circ} \mathrm{S}$ and in the northern hemisphere high latitudes), at most latitudes, the tendency is negative. Although the overall trend is negative in both cases, aerosols seem always to have an effect of opposite sign compared to greenhouse gases.

For low and mid-level clouds, greenhouse gases cause a slightly decreasing trend at low and mid latitudes, and an increase at high latitudes. The impact of aerosols on low and mid-level clouds is different in both hemispheres. In the southern hemisphere, except at very high latitudes, almost no trends in low and mid-level cloudiness are observed. This is expected, as the aerosol concentration in the $\mathrm{SH}$ is rather low. In the northern hemisphere, however, low and mid-level cloudiness increases under the influence of aerosols. A reason for this could be the second AIE. This question will be addressed in the following Section.

The minima in the trend in low-level cloudiness due to the aerosols observed around 40 and $60^{\circ} \mathrm{N}$ correspond to a decrease in cloudiness in limited regions (in the cases cited, over Himalaya, Greenland, and Alaska), counterbalancing the general increase.

\section{Influence of clouds on the SW radiative impact}

As stated in Section 3.2.2, greenhouse gases have a positive radiative impact in the SW spectrum due to the reduction in cloudiness, in particular at low levels. In the case of aerosols, however, two processes of opposite sign are acting. While the amount of low-level clouds increases, especially in northern hemisphere mid- 
latitudes, high-level cloud cover decreases. To isolate the effect of aerosols on cloudiness (or cloud water content) from the other aerosol effects acting in the SW spectrum (i.e., the ADE and the first AIE), we introduce a new quantity, $I_{a e r}^{\prime}$, defined as the radiative impact of aerosols minus the diagnosed radiative forcing due to the first AIE and the ADE:

$$
I_{\text {aer }}^{\prime}=I_{\text {aer }}-F_{A D E}-F_{1 \text { stAIE }}
$$

Equation 9

This quantity, $I_{a e r}^{\prime}$, is a measure of the second aerosol indirect effect and (other) cloud feedback processes associated to aerosol effects. It is positive, increasing from 0.2 to $0.4 \mathrm{Wm}^{-2}$ for the 1930 to 1989 period. Since the radiative impact in cloud-free conditions not explained by the direct radiative forcing of aerosols ( $I_{\text {aer }}^{c f}-F_{A D E}$ ) is very close to zero and limited to high latitudes, we infer that there are no major feedbacks acting except for processes involving clouds.

\section{Figure 8}

Figure 8 shows the zonal mean of the linear trends 1930-1989 of $I_{a e r}$ and $I_{a e r}^{\prime}$. The total aerosol radiative impact ( $I_{\text {aer }}$ ) is negative almost everywhere, with the lowest values in the northern hemisphere mid-latitudes. The radiative impact of the second AIE and cloud feedbacks ( $I_{a e r}^{\prime}$ ) is negative in northern hemisphere mid-latitudes, while it is positive in the region $40^{\circ} \mathrm{S}-20^{\circ} \mathrm{N}$. Analysis shows that high cloud cover and $I_{\text {aer }}^{\prime}$ trends are anticorrelated (correlation coefficient -0.38 for the globe, and -0.46 for the region mentioned). The increase in $I_{a e r}^{\prime}$ therefore may be attributed to the decrease in high-level cloud cover.

$I_{a e r}^{\prime}$ is negative in northern hemisphere mid-latitudes despite the reduction in high-level cloudiness. This may be attributed to the increase in low-level cloudiness, which we interpret as the second aerosol indirect effect, as shown in the following section. 


\section{The impact of the second aerosol indirect effect}

There are two possibilities, how a time-averaged increase in cloud-cover can be produced at a given grid-box. There is either an increase in cloud extent at each given time, or there is a longer persistence of a given cloud amount. The microphysical processes that convert cloud water into precipitation control the temporal extent of clouds, or their lifetime. The second indirect effect causes these processes to be slower for liquid water clouds, and thus will increase the persistence of clouds. We calculate the cloud lifetime in both scenarios, with and without anthropogenic aerosols. Cloud lifetime is defined here as the number of model timesteps (of 30min) per day, in which a gridbox is covered with fractional cloudiness above a threshold of $1 \%$. The results are not very sensitive to the exact choice of this threshold. Cloud lifetime is thus expressed in minutes per day. The global mean cloud lifetime for low level (total) cloudiness is $12 \mathrm{~h} 47 \mathrm{~min}$ (19h $54 \mathrm{~min}$ ) for the GHG+AER, $12 \mathrm{~h} 45 \mathrm{~min}$ (19h 53min) for the GHG, and $12 \mathrm{~h} 43 \mathrm{~min}$ (19h 52min) for the CTL scenario.

\section{Figure 9}

We show in Fig. 9 the zonal mean of the 1930 - 1989 linear trends in low-level cloud lifetime. The differences between the scenarios are shown to isolate the impact of the respective perturbations. Greenhouse gases decrease the cloud lifetime at low latitudes except inside the Inner-tropical convergence zone (ITCZ). The increase in cloud lifetime inside the ITCZ is linked to an increase in convection and thus in convective cloud cover, while the decrease in the subtropics is related to a drying of the atmosphere.

Except at two latitude bands $\left(40^{\circ} \mathrm{N}\right.$ and $60^{\circ} \mathrm{N}$, again due to regionally limited effects of opposite sign over Himalaya, and Greenland and Alaska, respectively), cloud lifetime increases strongly due to aerosols all over the northern hemisphere. The increase in low-level cloud cover is well correlated to the increase in cloud lifetime (correlation coefficient of 0.86). This suggests that the increase in cloud 
lifetime has played a significant role in the increase in low-level cloud cover. We quantify the increase in low-level cloud lifetime to 0.5 min day ${ }^{-1} \mathrm{decade}^{-1}$ in the

global mean for the period of the simulation in our model, with peak values up to 10 min day $^{-1}$ decade $^{-1}$ regionally and 3 min day $^{-1}$ decade $^{-1}$ in the zonal mean in the northern hemisphere mid-latitudes.

Water vapour lifetime is slightly affected by the imposed radiative forcing as well. Its mean value is around 8.1 days for the GHG+AER and GHG scenarios and 1\% lower in the CTL scenario. There is a linear trend of +0.03 days decade $^{-1}$ for the GHG+AER and GHG scenarios, and about half of that in the CTL scenario.

\section{Conclusions}

We investigated the radiative impacts of greenhouse gases and aerosols in a simulation of the $20^{\text {th }}$ century. Using the LMDZ GCM in a version forced by observed SST and sea ice distributions, we carried out three ensembles of simulations: a first ensemble where both greenhouse gases and sulfate aerosols were increased according to historical values, a second ensemble, where the aerosol distribution was fixed to pre-industrial values, and finally, a control ensemble, where the greenhouse gas concentrations were fixed to pre-industrial values as well.

Both greenhouse gases and aerosols impact strongly on longwave and shortwave radiative fluxes. While the increase in greenhouse effect due to greenhouse gases and the decrease in the SW radiative impact due to the aerosol direct effect are straightforward, the impact on radiation via the change of cloudiness is more complicated. The change in clouds in different atmospheric layers has a strong impact in both solar and terrestrial spectra.

Anthropogenic greenhouse gases cause the greenhouse effect of clouds to decrease in our model, and in addition, they result in a decrease in cloudiness, which reduces the radiative impact of anthropogenic greenhouse gases in the longwave spectrum. Similarly, clouds become less reflecting, yielding a positive radiative 
impact in the shortwave spectrum, which is enhanced by the reduction in cloudiness.

While the radiative impact of aerosols on the SW radiation is strongly negative, the radiative impact beyond the direct radiative forcing of aerosols and the first AIE is positive. It results from the second aerosol indirect effect that leads to an increase in cloud lifetime in low level clouds, particularly in the northern hemisphere (a negative radiative impact), and a decrease in high level cloudiness, resulting in a reduction in cloud albedo and thus a positive radiative impact. The trend in low-level cloud lifetime due to sulfate aerosols is quantified to $0.5 \mathrm{~min}$ day $^{-1}$ decade $^{-1}$ for the 1930 to 1989 period in the global mean in our model. These findings may be model-dependent. In particular, our parameterisation does not take into account the impact of aerosols on ice clouds. A future simulation with a complex microphysics scheme, treating both, liquid water and ice clouds, will be needed to confirm the findings on high-level clouds.

Our results suggest that it may not be appropriate to diagnose the second AIE as the difference between two simulations as proposed by Rotstayn and Penner (2001), because complex feedbacks involving high-level cloudiness are also at stake. However it should be noted that Rotstayn and Penner (2001) compare two runs, in which the aerosol concentrations change just in the precipitation scheme, whereas the first aerosol indirect effect is the same in both of their simulations. Consequently, the smaller perturbation of the radiative fluxes may limit feedback processes. Another slight difference is the use of fixed compared to transient SST distributions.

Our results provide a plausible explanation for the diminution of the temperature after the Second World War in the northern hemisphere. They confirm the finding of previous studies using other models (McAvaney et al., 2001; Mitchell et al., 2001) that the aerosol direct and indirect effects help to reproduce correctly the observed evolution of temperature over the $20^{\text {th }}$ century. 
Our analyses suggest that even in a simulation study using an atmospheric model forced by observed SST, a large amount of uncertainty remains regarding the feedback mechanisms, in particular those related to cloud processes. Further work is needed on the development and evaluation of general circulation model parameterizations, and in particular the parameterization of the aerosol indirect effects needs to be developed further.

\section{Acknowledgements}

The SST and sea ice extent data were provided by Dr. Nick Rayner of the Hadley Centre. GHG concentration data are from Dr. Gunnar Myhre of the Department for Geophysics, University of Oslo. Computer time was provided by IDRIS (Institut de Développement et des Resources en Informatique Scientifique) of the CNRS. We thank Dr. Zhao-Xin Li for many helpful discussions.

\section{References}

Albrecht BA (1989) Aerosols, cloud microphysics, and fractional cloudiness. Science 245:1227-1230

Boucher O, Anderson TL (1995) General circulation model assessment of the sensitivity of direct climate forcing by anthropogenic sulfate aerosols to aerosol size and chemistry. J Geophys Res 100:26117-26134

Boucher O, Haywood J (2001) On summing the components of radiative forcing of climate change. Clim Dyn 18:297-302

Boucher O, Lohmann U (1995) The sulfate-CCN-cloud albedo effect - a sensitivity study with two general circulation models. Tellus 47B:281-300 Boucher O, Pham M (2001) History of sulfate aerosol radiative forcings. Geoph Res Lett 29:1308 DOI 1029/2001GL014048

Boucher O, Le Treut H, Baker MB (1995) Precipitation and radiation modeling in a general circulation model: Introduction of cloud microphysical processes. J Geophys Res 100:16395-16414 Boucher O, Pham M, Venkataraman C (2002) Simulation of the atmospheric sulfur cycle in the Laboratoire de Météorologie Dynamique general circulation 
model. Model description, model evaluation, and global and European budgets. In Boulanger J-P, Li Z-X (eds) Note scientifique de l'IPSL 23, IPSL, Paris

Brenguier J-L, Chuang P, Fouquart Y, Johnson DW, Parol F, Pawlowska H, Pelon J, Schüller L, Schröder F, Snider J (2000) An overview of the ACE-2 CLOUDYCOLUMN closure experiment. Tellus 52B:815-827

Bréon F-M, Tanré D, Generoso S (2002) Aerosol effect on cloud droplet size monitored from satellite. Science 295:834-838

Cess RD, Zhang M-H, Potter GL, Barker HW, Colman RA, Dazlich DA, DelGenio AD, Esch M, Fraser JR, Galin V, Gates W, Hack JJ, Ingram JW, Kieht JT, Lacis AA, Le Treut H, Li Z-X, Liang X-Z, Mahfouf J-F, McAvaney BJ, Meleshko VP, Morcrett J-J, Randall DA, Roeckner E, Royer J-F, Sokolov AP, Sporyshev PV, Taylor KE, Wang W-C, Wetherald RT (1993) Uncertainties in carbon dioxide radiative forcing in atmospheric general circulation models. Science 262:1252-1255

Charlson RJ, Lovelock JE, Andrae MO, Warren SG (1989) Sulphate aerosols and climate. Nature 340:437-438

Coakley Jr, JA, Bernstein RL, Durkee PA (1987) Effect of ship-track effluents on cloud reflectivity. Science 237:1020-1022

Folland CK, Karl TR, Christy RA, Gruza GV, Jouzel J, Mann ME, Oerlemans J, Salinger MJ, Wand S-W (2001) Oberved climate variability and climate change. In Houghton JT, Ding Y, Griggs DJ, Noguer M, van der Linden PJ, Dai X, Maskell K, Johnson DJ (eds) Climate change 2001 - The scientific basis. Contribution of working group I to the Third Assessment Report of the Intergovernmental Panel on Climate Change. Cambridge University Press, Cambridge, pp 99-182

Fouquart Y, Bonnel B (1980) Computations of solar heating of the Earth's atmosphere: A new parameterization. Cont Atmos Phys 53:35-62 Hansen J, Sato M, Ruedy R (1997) Radiative forcing and climate response. J Geophys Res 102:6831-6864 Kaufman YJ, Nakajima T (1993) Effect of Amazon smoke on cloud microphysics and albedo - analysis from satellite imagery. J Appl Meteorol 32:729-744 
Le Treut H, Li X-Z (1991) Sensitivity of an atmospheric general circulation model to prescribed SST changes: Feedback effects associated with the simulation of cloud optical properties. Clim Dyn 5:175-187

Le Treut H, Forichon M, Boucher O, Li Z-X (1998) Sulfate aerosol indirect effect and $\mathrm{CO}_{2}$ greenhouse forcing: Equilibrium response of the LMD GCM and associated cloud feedbacks. J Clim 11:1673-1684

Li Z-X (1999) Ensemble atmospheric GCM simulation of climate interannual variability from 1979 to 1994 . J Clim 12:986-1001

McAvaney BJ, Covey C, Joussaume S, Kattsov V, Kitoh A, Ogana W, Pitman AJ, Weaver AJ, Wood RA, Zhao Z-C (2001) Model evaluation. In Houghton JT, Ding Y, Griggs DJ, Noguer M, van der Linden PJ, Dai X, Maskell K, Johnson DJ (eds) Climate change 2001 - The scientific basis. Contribution of working group I to the Third Assessment Report of the Intergovernmental Panel on Climate Change. Cambridge University Press, Cambridge, pp 471-524

Mitchell JFB, Karoly DJ, Hegerl GC, Zwiers FW, Allen MR, Marengo J (2001) Detection of climate change and attribution of causes. In Houghton JT, Ding Y, Griggs DJ, Noguer M, van der Linden PJ, Dai X, Maskell K, Johnson DJ (eds) Climate change 2001 - The scientific basis. Contribution of working group I to the Third Assessment Report of the Intergovernmental Panel on Climate Change. Cambridge University Press, Cambridge, pp 695-738

Morcrette J-J (1991) Evaluation of model-generated cloudiness: Satellite-observed and model-generated diurnal variability of brightness temperature. Mon Wea Rev 119:1205-1224

Myhre G, Myhre A, Stordal F (2001) Historical evolution of radiative forcing of climate. Atmos Environ 35:2361-2373

Pontikis CA, Hicks EM (1993) Droplet activation as related to entrainment and mixing in warm tropical marine clouds. J Atmos Sci 50:1888-1896

Ramanathan, Crutzen P, Lelieveld J, Mitra AP, Althausen D, Anderson J, Andrae MO, Cantrell W, Cass GR, Chung CE, Clarke AD, Coakley Jr. JA, Collins WA, Conant WC, Dulac F, Heintzenberg BJ, Heymsfield AJ, Holben B, Howell S, Hudson CJ, Jayaraman A, Kiehl JT, Krishnamurti TN, Lubin DD, McFarquhar G, Novakov T, Ogren J, Poddorny EIA, Prather K, Priestly K, Prospero JM, Quinn 
FPK, Pajeev K, Rasch P, Rupert S, Sadourny R, Satheesh GSK, Shaw GE, Sheridan P, Valero FPJ (2001) Indian Ocean Experiment: An integrated analysis of the climate forcing and effects of the great Indo-Asian haze. J Geophys Res 106:28371-28398

Ramaswamy V, Boucher O, Haigh J, Hauglustaine D, Haywood J, Myhre G, Nakajima T, Shi GY, Solomon S (2001) Radiative forcing of climate change. In Houghton JT, Ding Y, Griggs DJ, Noguer M, van der Linden PJ, Dai X, Maskell K, Johnson DJ (eds) Climate change 2001 - The scientific basis. Contribution of working group I to the Third Assessment Report of the Intergovernmental Panel on Climate Change. Cambridge University Press, Cambridge, pp 349-416 Rayner NA, Parker DE, Horton EB, Folland CK, Alexander LV, Rowell DP, Kent EC, Kaplan A (2003) Global analyses of SST, sea ice and night marine air temperature since the late nineteenth century. J Geophys Res 108:4407 DOI 10.1029/2002JD002670

Rosenfeld D (2000) Suppression of rain and snow by rban and industrial air pollution. Science 287:1793-1796

Rotstayn LD and Penner JE (2001) Indirect aerosol forcing, quasi-forcing and climate response. J Clim 14:2960-2975

Sexton DMH, Grubb H, Shine KP, Folland CK (2003) Design and analysis of climate model experiments for the efficient estimation of anthropogenic signals. $\mathbf{J}$ Clim 16:1320-1336

Stephens GL (1978) Radiation profiles in extended water clouds. II:

Parameterization schemes. J Atmos Sci 35:2123-2132

Tiedtke M (1989) A comprehensive mass flux scheme for cumulus parameterization in large-scale models. Mon Wea Rev 117:1779-1800 Twomey S (1974) Pollution and the planetary albedo. Atmos Environ 8:12511256

Wigley TML (1989) Possible climate change due to $\mathrm{SO}_{2}$-derived cloud condensation nuclei. Nature 339:365-367

\begin{tabular}{|l|l|l|l|}
\hline & GHG+AER & GHG & CTL \\
\hline Greenhouse gases & time-varying & time-varying & pre-industrial \\
\hline Sulfate Aerosols & time-varying & pre-industrial & pre-industrial \\
\hline
\end{tabular}


Table 1: Summary of the forcings in the three ensembles. Throughout the paper, we will use upper case abbreviations to name the simulations, and lower case, if the forcing itself is meant.

$\mathrm{I}_{\mathrm{SW}, \text { aer }} \quad=\left\langle\mathrm{F}_{\mathrm{SW}, \mathrm{GHG}+\mathrm{AER}}\right\rangle \quad-\left\langle\mathrm{F}_{\mathrm{SW}, \mathrm{GHG}}\right\rangle$

$\mathrm{I}_{\mathrm{SW}, \mathrm{ghg}}=\left\langle\mathrm{F}_{\mathrm{SW}, \mathrm{GHG}}\right\rangle \quad-\left\langle\mathrm{F}_{\mathrm{SW}, \mathrm{CTL}}\right\rangle$

$\mathrm{I}_{\mathrm{LW}, \text { aer }} \quad=\left\langle\mathrm{GHE}_{\mathrm{GHG}+\mathrm{AER}}\right\rangle \quad-\left\langle\mathrm{GHE}_{\mathrm{GHG}}\right\rangle$

$\mathrm{I}_{\mathrm{LW}, \text { ghg }}=\left\langle\mathrm{GHE}_{\mathrm{GHG}}\right\rangle \quad-\left\langle\mathrm{GHE}_{\mathrm{CTL}}\right\rangle$

Table 2: Definition of the SW and LW radiative impacts of aerosols and greenhouse gases. The brackets indicate ensemble averaging. The total greenhouse effect GHE is defined in the text.

\begin{tabular}{|l|l|l|l|}
\hline & GHG+AER & GHG & CTL \\
\hline Total & $64.21 \%$ & $64.06 \%$ & $63.92 \%$ \\
\hline High level & $40.64 \%$ & $40.71 \%$ & $40.65 \%$ \\
Mid level & $21.75 \%$ & $21.47 \%$ & $21.46 \%$ \\
Low level & $37.76 \%$ & $37.52 \%$ & $37.42 \%$ \\
\hline
\end{tabular}

Table 3: Global mean values of the cloud cover for the three layers and total cloud cover, for the three scenarios, for the whole period (1930 - 1989). 


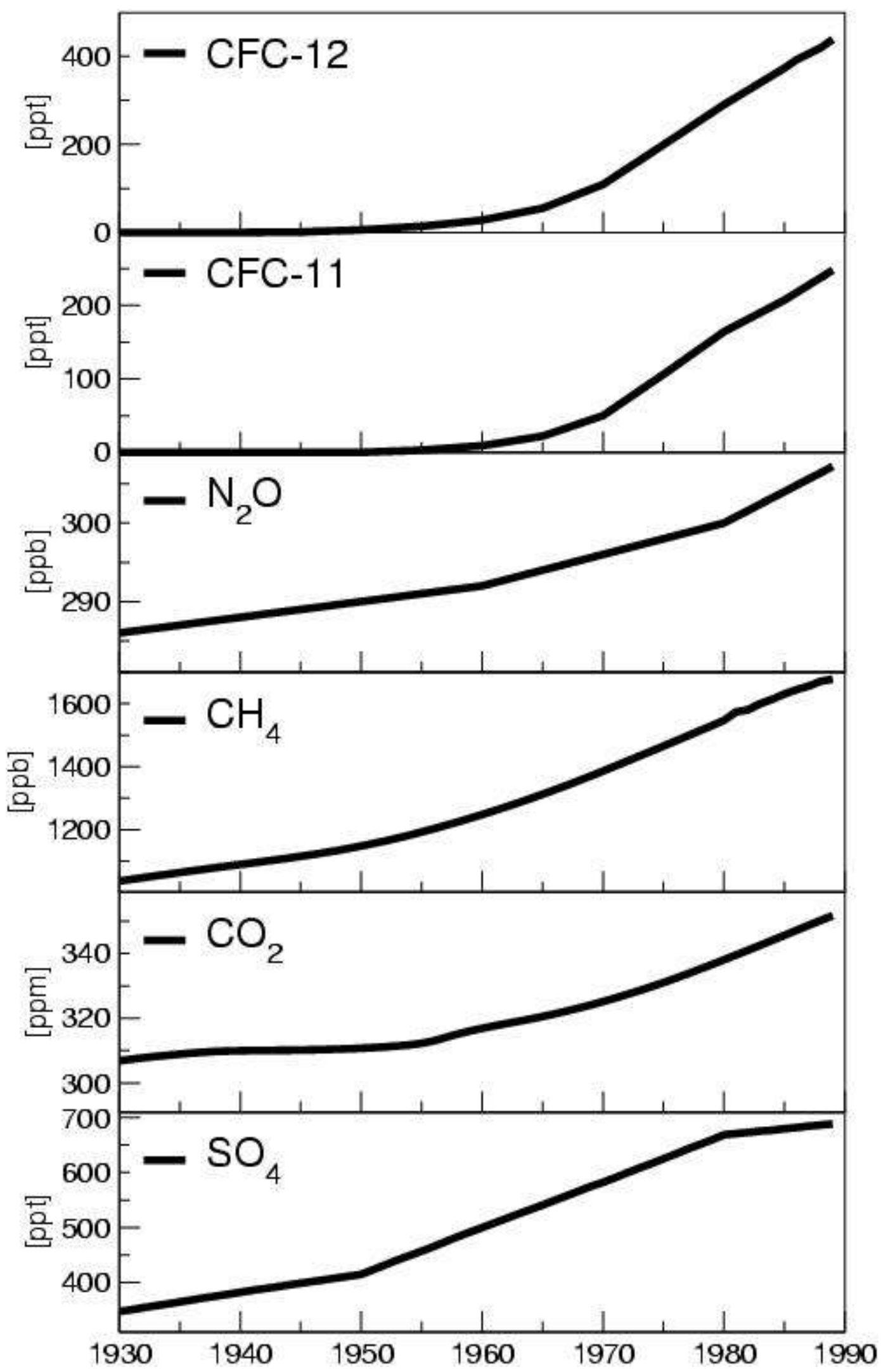

<so4ghg.eps>

Figure 1: The evolution of the sulfate aerosol mass concentration $(850 \mathrm{hPa}$, Boucher and Pham, 2001) and greenhouse gas (Myhre et al., 2001) concentrations. Global and annual means are shown. 
(a) <tops.eps> (b) <topl.eps>
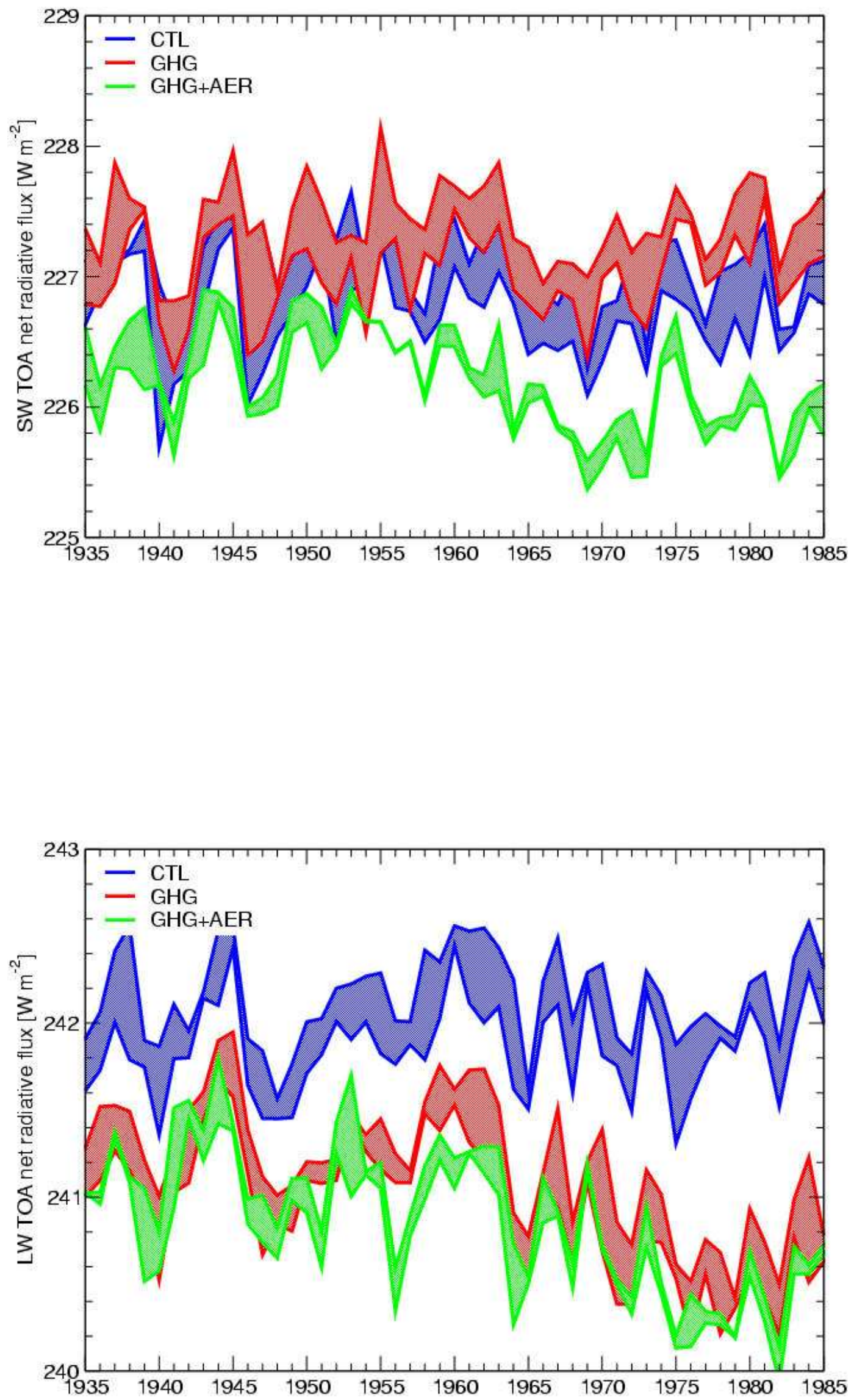
Figure 2 : Evolution of the global annual mean net radiative flux at TOA (a) shortwave and (b) longwave spectrum. An 11-year running mean is applied. The shaded areas represent the envelope of the three simulations for each scenario. In blue, CTL, in red, GHG, and in green, GHG+AER simulations.

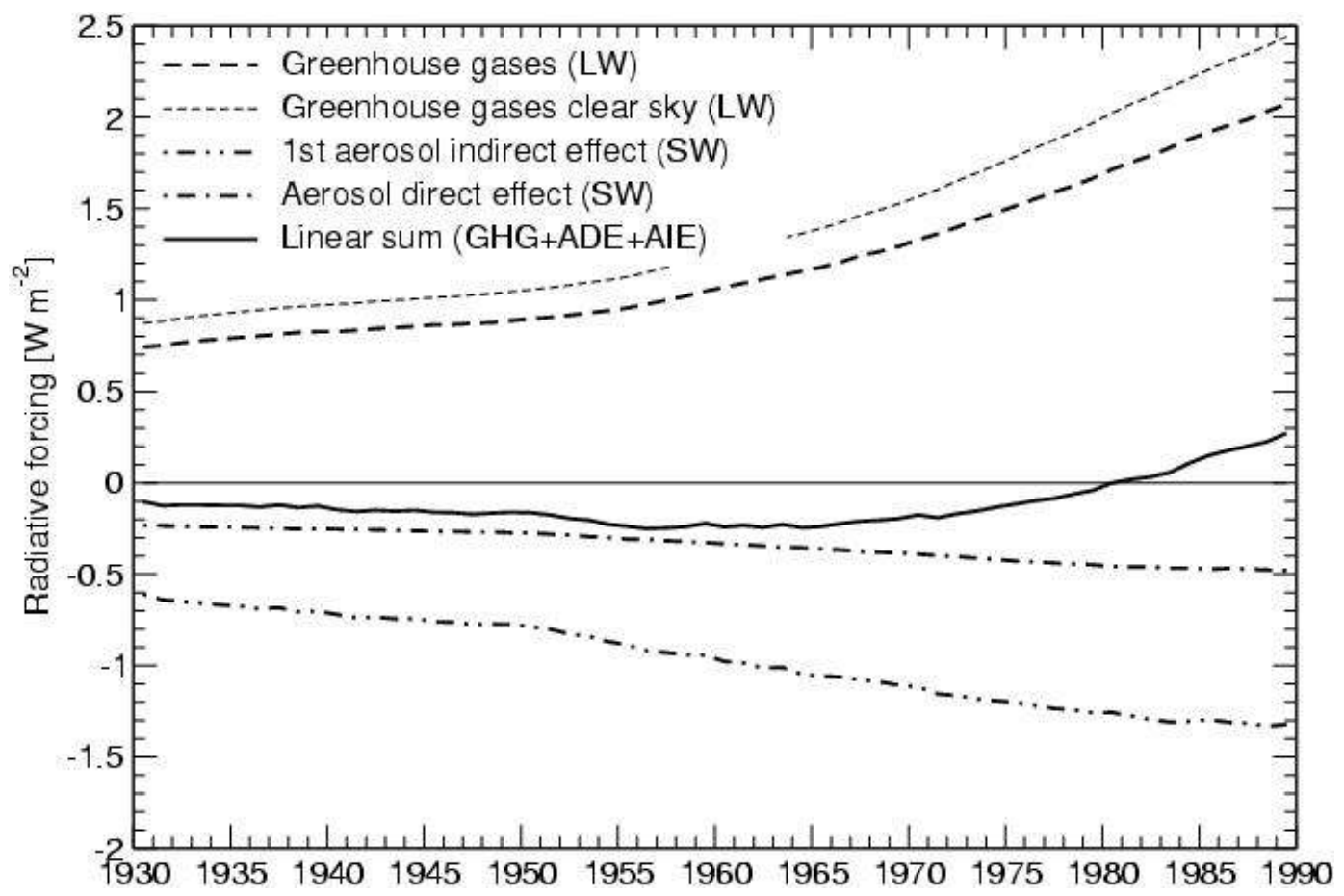

<forcings.eps>

Figure 3: Annual global mean radiative forcings $\left[\mathrm{Wm}^{-2}\right]$ as diagnosed in the ensemble mean of the GHG+AER simulations: greenhouse gas forcing (LW spectrum, dashed line), aerosol direct forcing (SW spectrum, dot-dashed), and first aerosol indirect forcing (SW, dot-dot-dashed). The solid line corresponds to the sum of the three diagnosed radiative forcings. 


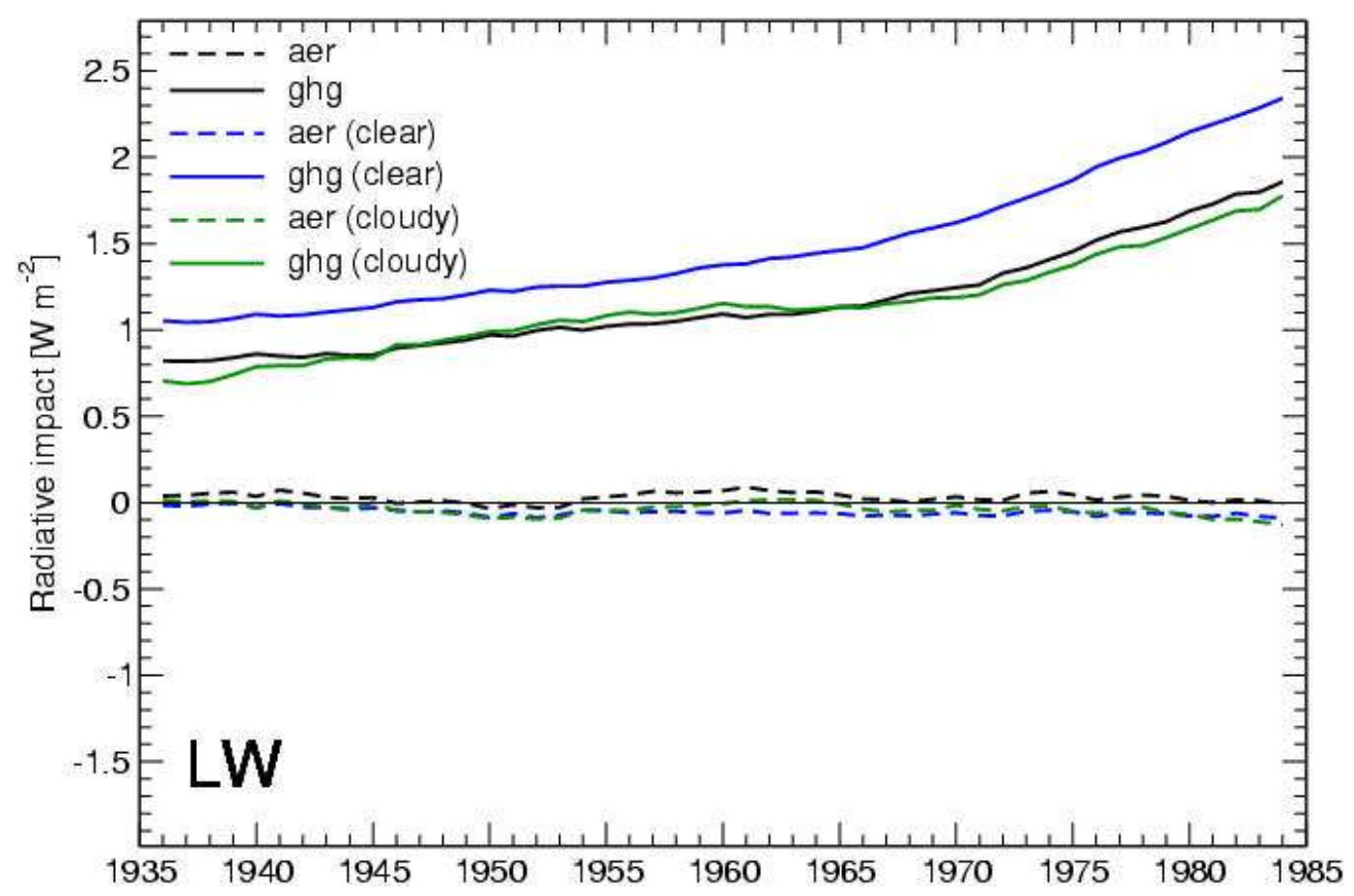

<rimpacts_lw.eps>

Figure 4: Global annual means of the change in total greenhouse effect (GHE) $\left(\mathrm{Wm}^{-2}\right.$, as defined in section 2.4.1), for aerosols and greenhouse gases, for all-sky (black), cloud-free (blue) and cloud covered (green) conditions. An 11-year running mean is applied.

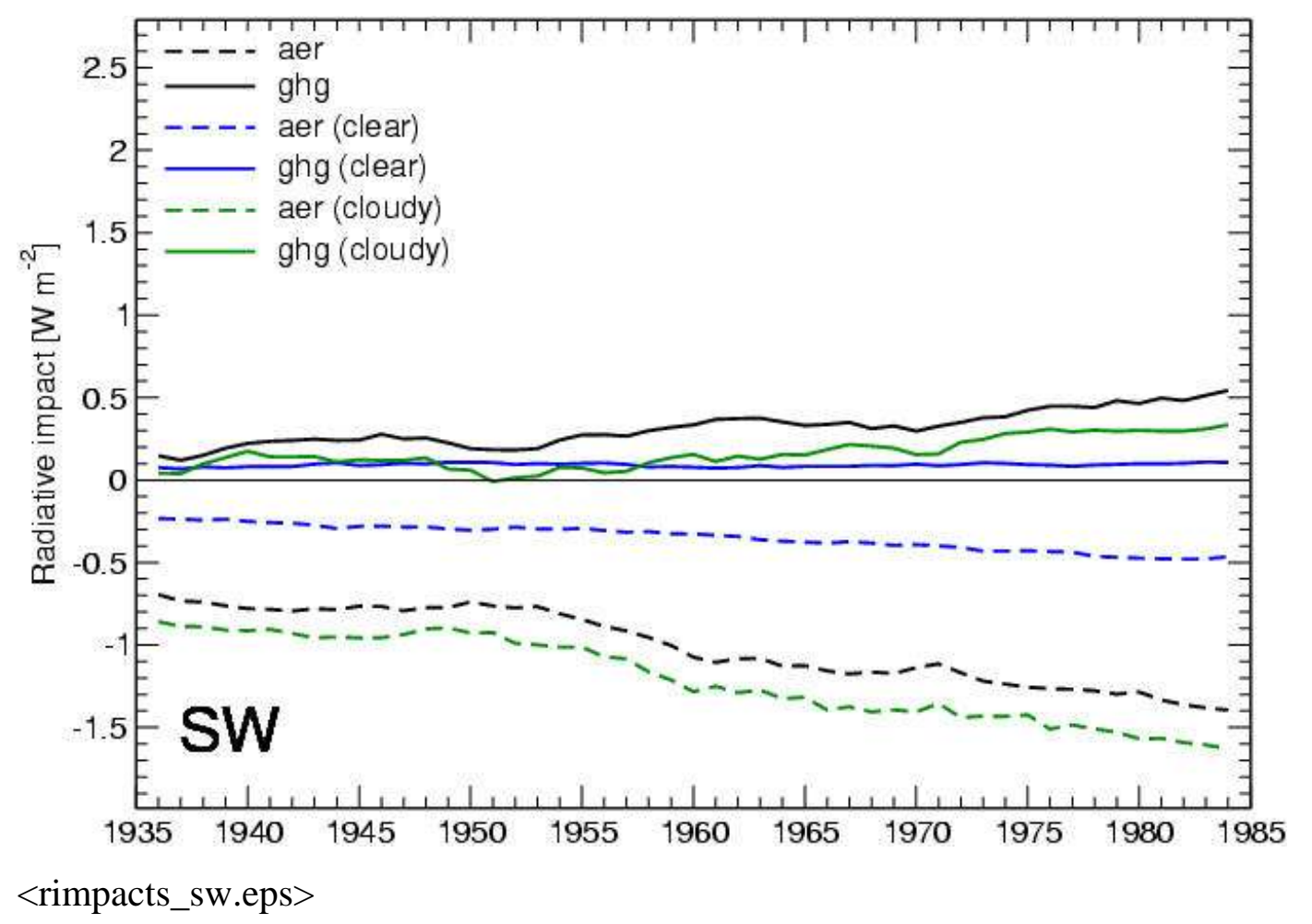

Figure 5: Global annual means of the shortwave radiative impacts $\left(\mathrm{Wm}^{-2}\right.$, as defined in section 2.4.2), for aerosols and greenhouse gases. An 11-year running mean is applied. 


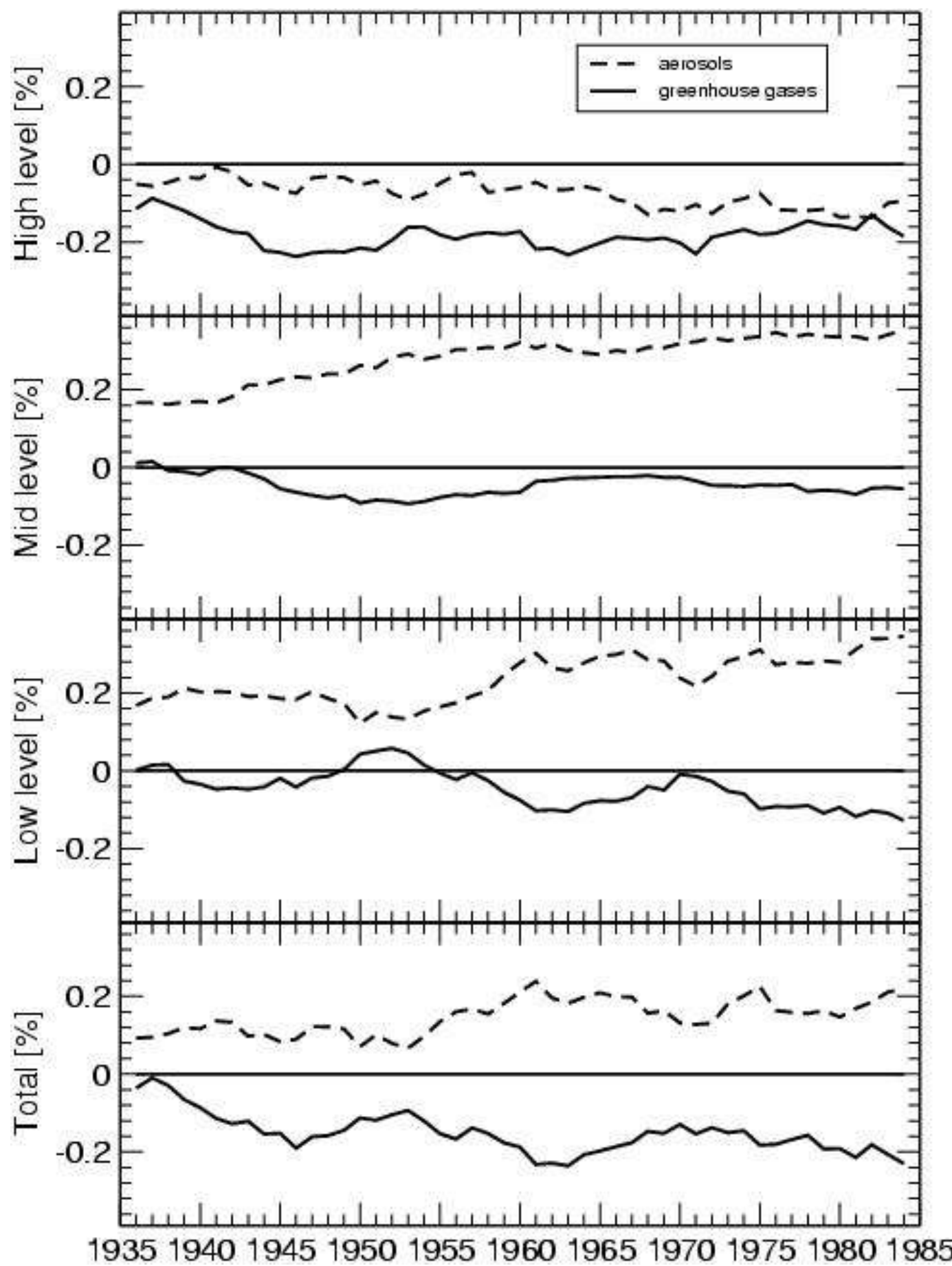

<cloudevol.eps>

Figure 6: Temporal evolution of the annual and global mean cloudiness. The differences between ensemble means are shown. The evolution for high level (above $450 \mathrm{hPa}$ ), mid level (between 800 $\mathrm{hPa}$ and $450 \mathrm{hPa}$ ), and low level clouds (below $800 \mathrm{hPa}$ ), and the total cloudiness is shown. An 11-year running mean is applied. 


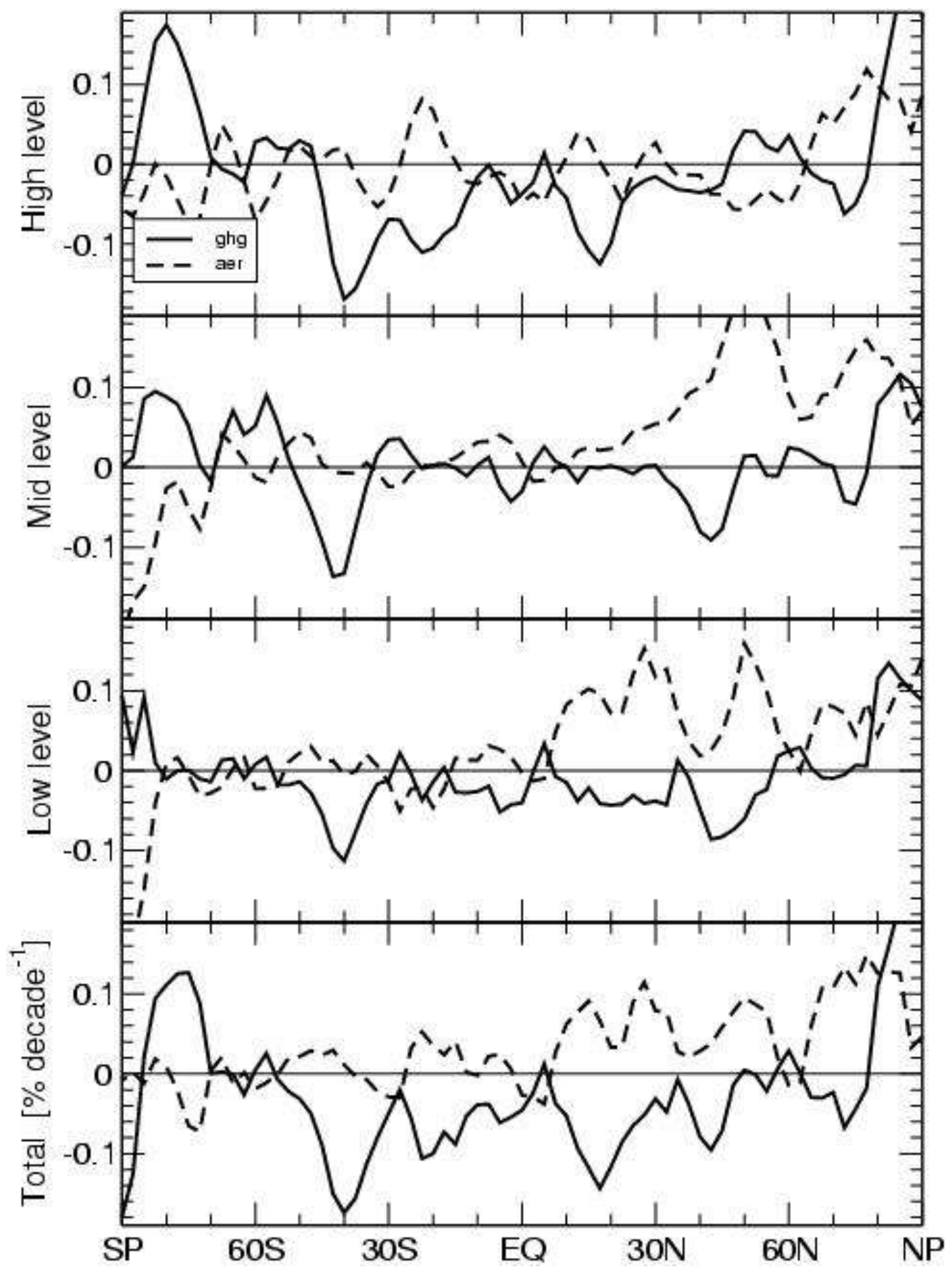

<cloudtrends.eps>

Figure 7: Zonal mean of the linear trends in the annual mean high level, low level, and total cloudiness. The differences between ensemble means are shown, as in Fig. 4. 


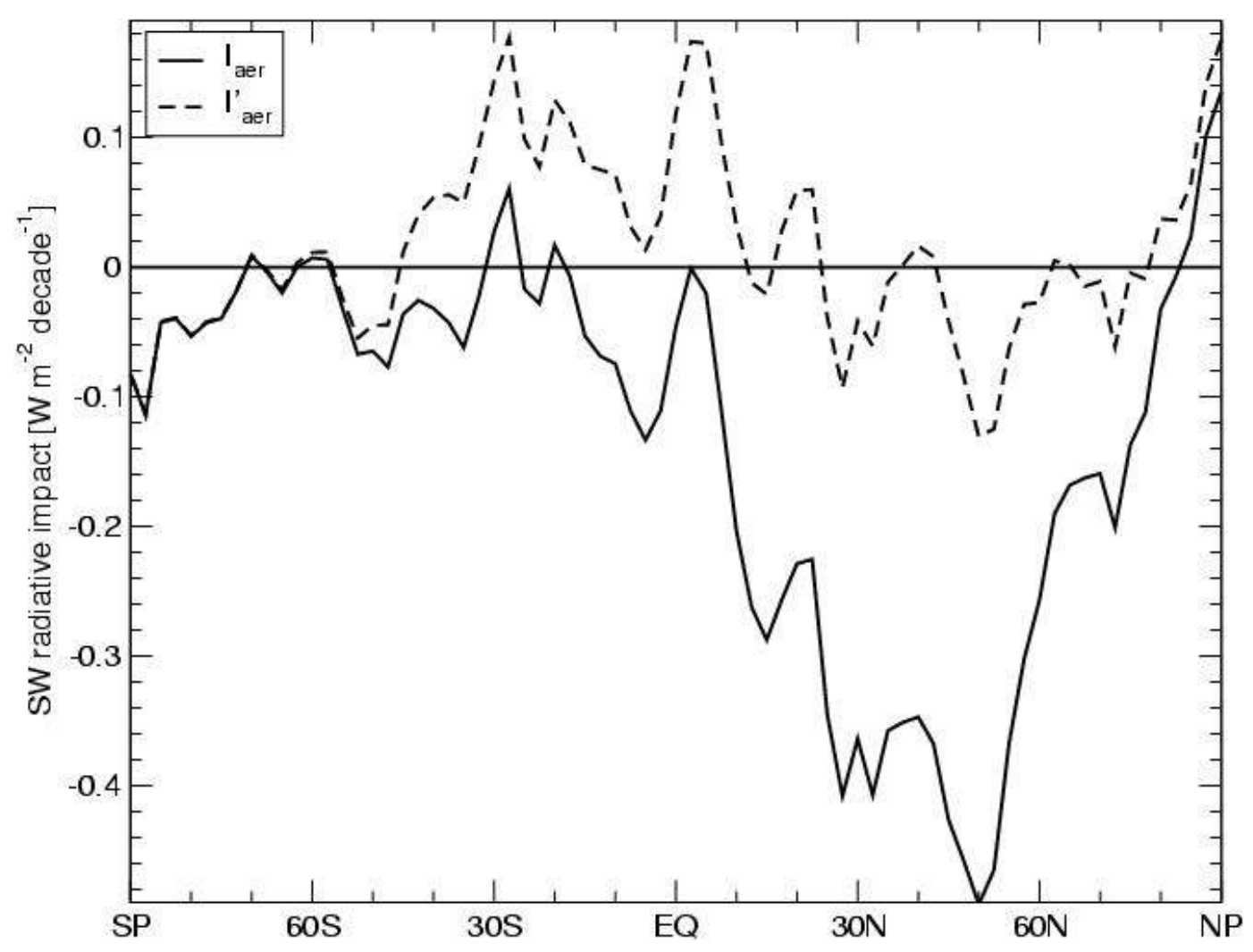

<topstrends.eps>

Figure 8: Zonal mean linear trends in the annual mean SW radiative impact of the aerosols as defined in section 2.4.2 ( $I_{\text {aer }}$, solid line) together with the radiative impact of second AIE and cloud feedbacks ( $I_{a e r}^{\prime}$, dashed line). 


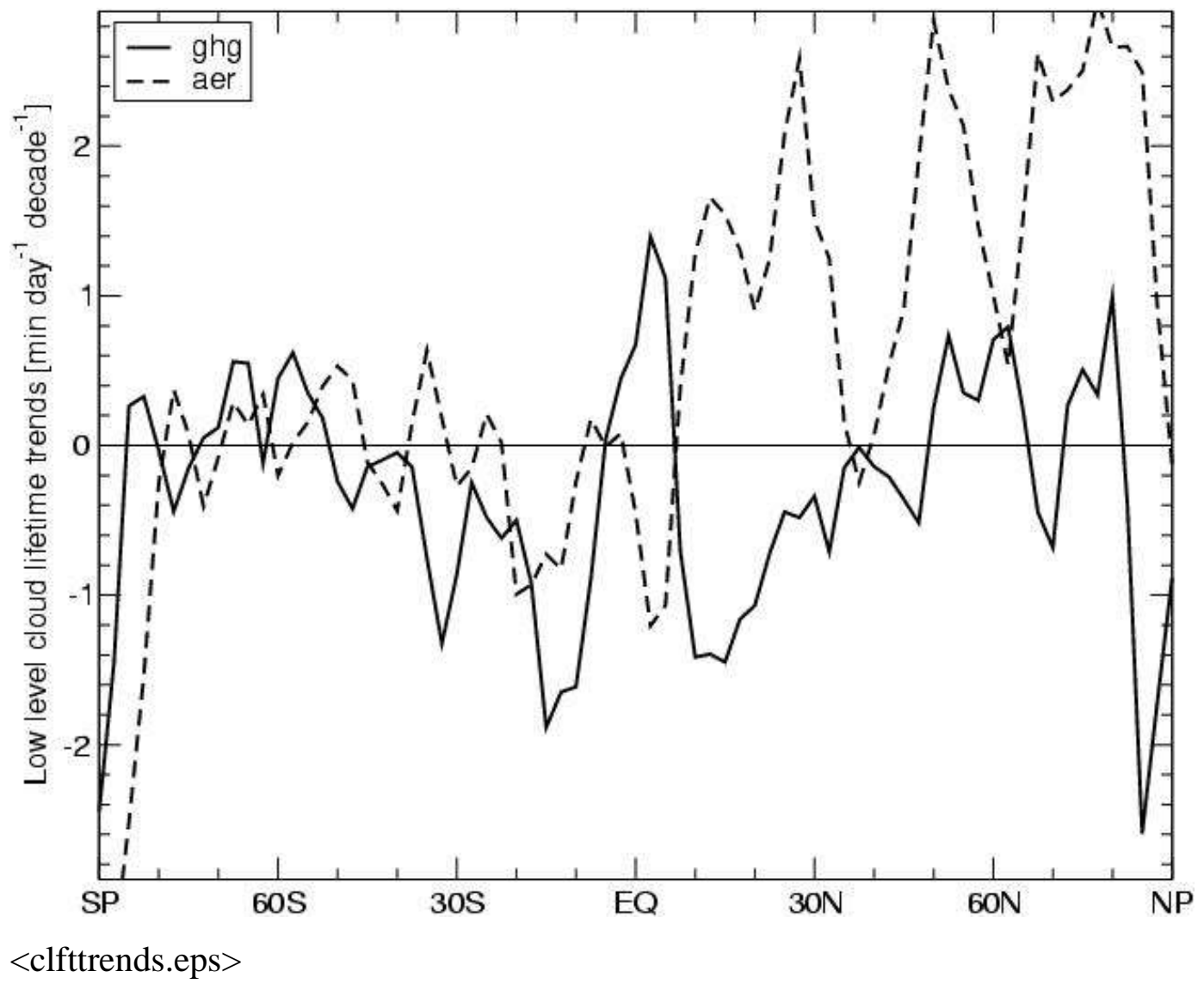

Figure 9: Zonal mean linear trends of the annual mean diurnal lifetime of low-level clouds (min day $^{-1}$ decade $\left.^{-1}\right)$. Differences between scenarios are shown as in Fig. 4. 